\title{
Fabry's Disease Presenting as Stroke in a Young Female
}

\author{
Paul S. Giacomini, Patrick T. Shannon, Joe T.R. Clarke, Cheryl Jaigobin
}

\begin{abstract}
Background: Fabry's disease is an X-linked disorder, caused by a deficiency of the lysosomal enzyme $\alpha$-galactosidase A which results in the accumulation of the glycosphingolipid, ceramide trihexose in the vascular endothelium and can lead to cerebral infarction. Male hemizygotes are generally more severely affected than heterozygote females. Clinical disease in females is thought to be due to unequal X chromosome inactivation. Case: A 19-year-old woman, who was previously well, presented with neurological deficits secondary to basal ganglia and pontine infarction. Extensive cardiac, arterial and hematologic investigations did not identify the etiology of her stroke. Muscle biopsy revealed endothelial lysosomal aggregates most consistent with a diagnosis of Fabry's disease. The diagnosis was confirmed on the basis of molecular genotype analysis. Discussion: Inherited causes of stroke such as Fabry's disease should be considered in young patients with stroke if an etiologic diagnosis is not reached after complete investigations. Muscle biopsy can assist with the diagnosis and guide further investigations. This report summarizes the biochemical and histological features of Fabry's disease and the associated genetic abnormalities.
\end{abstract}

RÉSUMÉ: Accident vasculaire cérébral comme mode de présentation de la maladie de Fabry chez une jeune femme. Introduction: La maladie de Fabry est une maladie liée à l'X causée par un déficit en a-galactosidase A, une enzyme lysosomiale, qui provoque l'accumulation de céramide trihexose, un glycosphingolipide, dans l'endothélium vasculaire et peut causer des infarctus cérébraux. Les hommes hémizygotes sont généralement plus atteints que les femmes hétérozygotes. La maladie chez les femmes serait due à une inactivation inégale du chromosome X. Présentation de cas: Une femme âgée de 19 ans, en bonne santé, a consulté pour des déficits neurologiques secondaires à un infarctus au niveau des noyaux gris centraux et du pont. Une investigation cardiaque, artérielle et hématologique poussée n'a pas identifié l'étiologie de son accident vasculaire cérébral (AVC). Une biopsie musculaire a montré, au niveau de l'endothélium, des agrégats lysosomiaux compatibles avec un diagnostic de maladie de Fabry. Le diagnostic a été confirmé par analyse génotypique. Discussion: Les causes héréditaires d'AVC telles la maladie de Fabry devraient faire partie du diagnostic différentiel chez les jeunes patients qui subissent un AVC, si une investigation complète ne permet pas de poser un diagnostic étiologique. La biopsie musculaire peut aider au diagnostic et guider l'investigation. Nous présentons un sommaire des manifestations biochimiques et histologiques de la maladie de Fabry et les anomalies génétiques associées.

Can. J. Neurol. Sci. 2004; 31: 112-114

A 19-year-old woman presented with acute dysarthria and left sensorimotor impairment. Although she has a history of migraine, her presentation was not associated with headache. She was eight weeks pregnant. Her known family history was negative for vascular disease, but her mother was adopted. Her general physical examination was unremarkable. On neurological examination, there was left facial weakness in an upper motor neuron pattern and dysarthria. On motor examination there was a left hemiparesis in which power was evaluated at $4 / 5$ in a pyramidal distribution. This was associated with left-sided hyperreflexia and an extensor plantar response. There was impaired sensation on the left side to pain and temperature.

Magnetic resonance imaging (MRI) of the brain at presentation showed signal changes in the basal ganglia suggestive of inflammatory disease or infarction (Figure 1A). Although there was no clinical change, a repeat MRI one week after the initial study confirmed the presence of bilateral basal ganglia infarction (Figure 1B) and revealed a new left pontine infarct (Figure 1C: arrowhead). There was also evolution of the initial lesions with hemorrhagic conversion of the left putaminal lesion.

A number of investigations were arranged to identify the etiology of the multiple strokes in this patient. Potential cardiac sources of emboli to the brain were investigated and excluded by transthoracic and transesophageal echocardiography. A cerebral angiogram did not show evidence of vasculitis. A hematologic assessment was performed and

From the McGill University Health Center, Department of Neurology and Neurosurgery (PSG), Montreal, Quebec; Department of Neuropathology (PTS); Department of Pediatrics (JTRC); and Department of Neurology (CJ); University of Toronto School of Medicine, Toronto, Ontario, Canada .

ReCEIVEd MARCh 21, 2003. ACCEPTED In FINAL FORM June 25, 2003. Reprint requests to: Cheryl Jaigobin, University of Toronto, Division of Neurology, Toronto General Hospital, University Health Network, Eaton North 11-215, 200 Elizabeth Street, Toronto, Ontario M5G 2C4 


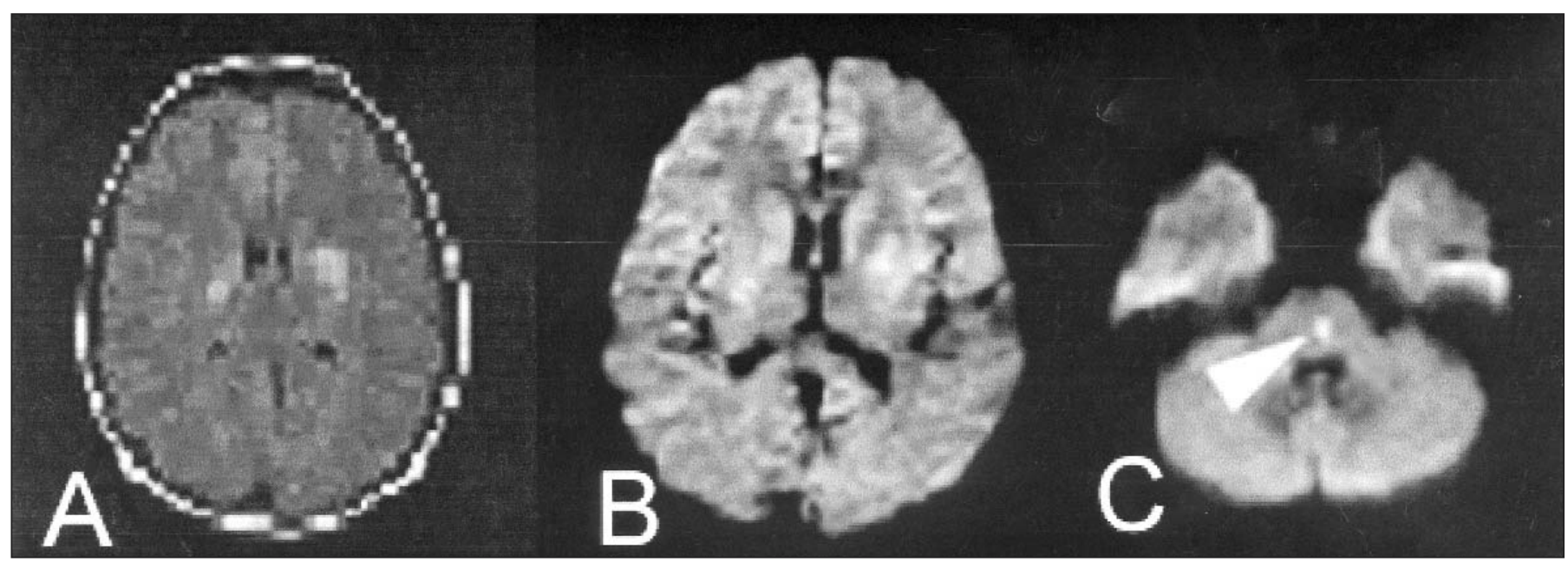

Figure 1: A) Initial MRI Flair sequences showing bilateral increased signal in the region of the basal ganglia, which one week later $\boldsymbol{B})$ were bright on diffusion weighted imaging. In addition, a new lesion was detected in the basis pontis $\boldsymbol{C}$ ) indicated by the arrowhead.

there was no evidence of a hypercoagulable state. In the absence of an etiological diagnosis, inherited causes of stroke including mitochondrial disease and cerebral autosomal dominant arteriopathy with subcortical infarcts and leukoencephalopathy (CADASIL) were considered and a left deltoid muscle biopsy was obtained. The tissue was frozen in liquid isopentane for cryostat sections according to routine protocols. Tissue for ultrastructural examination was fixed in glutaraldehyde, post fixed in Osmium tetroxide, embedded in Epon resin, and counterstained with Uranyl Acetate and Lead Citrate, and examined on a Phillips EM400 electron microscope.

Cryostat sections of the muscle biopsy revealed prominence and vacuolation of the vascular endothelium and subtle vacuolation of smooth muscle elements. The vacuolations stained with Luxol Fast Blue (Figure 2A). Ultrastructural examination identified numerous, highly pleomorphic lysosomes in vascular endothelial and smooth muscle cells (Figure 2B). These contained a variety of periodic membranous profiles with a periodicity of approximately $5 \mathrm{~nm}$, and occasional concentric profiles and linked rings (Figure 2C). The abnormal lysosomes were not present in skeletal muscle cells. These pathological findings were suggestive of Fabry's disease.

Subsequent investigations included slit lamp examination of the cornea which revealed corneal dystrophy. Her creatinine clearance was mildly impaired, though serum creatinine levels were within normal limits. Measurement of $\alpha$-galactosidase A in peripheral blood leukocytes showed activity in the normal range $(21 \mathrm{nmol} / \mathrm{h} / \mathrm{mg}$ protein; normal, 13 $38 \mathrm{nmol} / \mathrm{h} / \mathrm{mg}$ ). However, the level of the glycosphingolipid, ceramide trihexoside in plasma was elevated to $4.56 \mathrm{nmol} / \mathrm{ml}$ (normal, 1.7-2.3 $\mathrm{nmol} / \mathrm{ml}$ ) and consistent with Fabry's disease. The diagnosis was confirmed by sequencing of the GLA gene from DNA extracted from peripheral blood. This showed a new missense mutation in the coding sequence with a single-base transition (C776T) causing a substitution of leucine for proline at codon 259. The patient was heterozygous for this mutation. There were also two intronic polymorphisms, 640-16 A->G and 1000-22 C->T in the GLA gene.

Based on the above findings, a diagnosis of stroke secondary to Fabry's disease in a heterozygous female was made. Enzyme replacement therapy with recombinant $\alpha$-galactosidase A (Replagal ${ }^{\circledR}$ ) has since been administered every two weeks by intravenous infusion. At one year after initiating therapy, there have been no episodes of recurrent stroke.

\section{Discussion}

Fabry's disease is a sex linked recessive condition due to a defect of the alpha galactosidase A gene on the long arm of the $\mathrm{X}$ chromosome. ${ }^{1}$ Deficiency of the enzyme leads to accumulation of the neutral glycosphingolipid, ceramide trihexoside in the plasma and lysosomes of vascular endothelial and smooth muscle cells and both ceramide trihexoside and digalactosylceramide in kidney. ${ }^{1}$ The progressive accumulation in the endothelial cells lead to ischemia and infarction, the hallmarks of the disease. The brain is usually most affected by small infarcts of penetrating arteries. ${ }^{1}$ The lipids also accumulate in the smooth muscle cells of the cardiovascular and renal system as well as in epithelial cells of the cornea. ${ }^{1}$ The disease phenotype is characterized by angiokeratomas, acroparesthesias, corneal and lenticular opacities and cardiac and renal dysfunction. ${ }^{1}$

The diagnosis of Fabry's disease in this case was strongly suggested by the muscle biopsy. The pattern of endothelial accumulation of phospholipids within lysosomes is characteristic of Fabry's disease. The ultrastructural pattern of lysosomal disease in this patient which demonstrated periodic membrane profiles of light and dark bands is also consistent with this diagnosis. $^{2}$

Metabolic screening showed normal $\alpha$-galactosidase A activity in leukocytes, a common finding in Fabry's disease carriers. ${ }^{1}$ However, the elevation in the plasma level of the glycosphingolipid, ceramide trihexoside was consistent with Fabry's disease. ${ }^{1}$ The diagnosis was confirmed by sequencing of the GLA gene, which showed a missense mutation in the coding sequence and two intronic molecular polymorphisms. Female heterozygotes are usually asymptomatic or have a mild form of the disease. However, there have been reports of females displaying symptoms similar to hemizygous males. ${ }^{3,4}$ This 


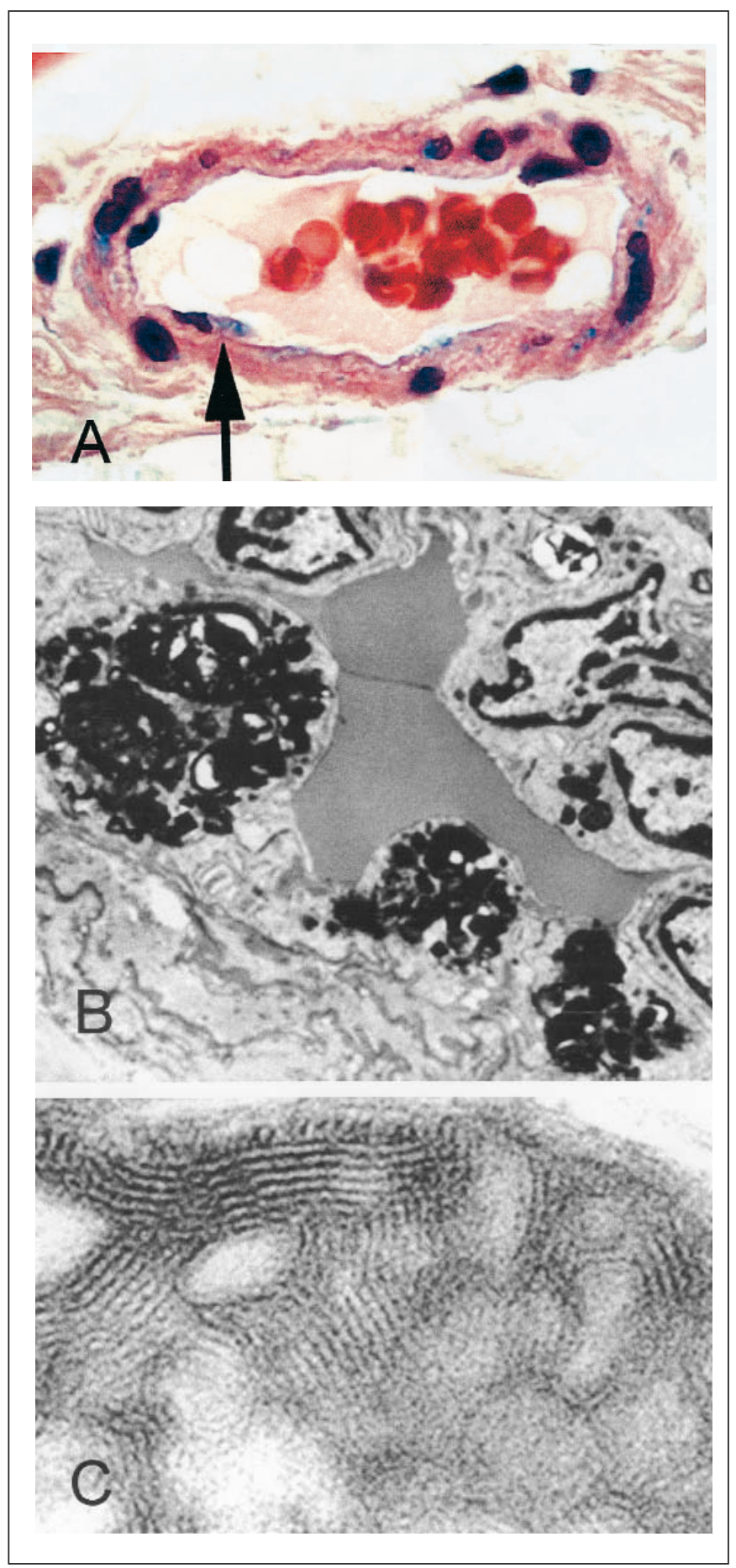

Figure 2: Muscle biopsy: A) $H+E$ stained section counterstained with Luxol Fast Blue, demonstrating small muscular artery. The endothelial cells (arrow) are staining bright blue, indicating an accumulation of phospholipid (Original magnification $x$ 630). B) Ultrastructural examination reveals massive accumulation of electron dense material within endothelial cells of intramuscular vessels. (Original magnification $x$ 5000). C) Higher magnification demonstrates membrane bound organelles containing a variety of pleomorphic laminated structures (Original magnification x 10,000) variable expression is attributed to random $X$ inactivation. ${ }^{1,5}$

The incidence of stroke in young adults has been estimated as 10 cases per 100,000 per year. ${ }^{6}$ Identified causes include cardiac and arterial disease and hematologic abnormalities. In one series, up to sixty causes of stroke were identified. ${ }^{7}$ However, in 10$32 \%$ of patients, despite extensive investigations, an etiologic diagnosis is not reached..$^{8,9}$ Although both cerebral infarction and hemorrhage have been described in Fabry's disease, stroke as a presentation in a heterozygote is uncommon. ${ }^{10}$ While $70 \%$ of heterozygotes present with other manifestations such as corneal dystrophy, a much smaller proportion $(>10 \%)$ will develop peripheral neuropathy and stroke. ${ }^{1,4}$ Although the literature describing stroke in both hemizygotes and heterozygotes with Fabry's disease is limited, existing reports confirm that this is a cause of stroke in the young and suggest a predilection for these ischemic events in the vertebrobasilar circulation. ${ }^{10}$ This has been attributed to ectatic changes in these arteries. Another potential mechanism is progressive vascular occlusion as a result of glycosphingolipid deposition in arterial walls. As in our patient, there are also reports of hemorrhagic stroke in patients with Fabry's disease. Again the mechanism has been attributed to vascular ectasia and to a weakening of the arterial wall by glycosphingolipid accumulation. ${ }^{10}$

The muscle biopsy in this case was performed to investigate for inherited causes of stroke including cerebral autosomal dominant arteriopathy with subcortical infarction and leukoencephalopathy, and mitochondrial cytopathy. However, careful attention to subtle histological features led to the ultrastructural diagnosis, which was ultimately confirmed by genotypic analysis. This case serves to illustrate the diagnostic utility of muscle biopsy in patients with stroke of undetermined origin, as a means of directing further genetic analyses and therapy.

\section{REFERENCES}

1. Desnick RJ, Ioannou YA, Eng CH. Alpha galactosidase A deficiency: Fabry disease. In: Scriver CR, Beaudet AL, Sly WS, Valle D (Eds). The Metabolic \& Molecular Bases of Inherited Disease. 8th ed. McGraw Hill 2001: 3733-3774.

2. Elleder M, Ledvinova J, Vosmik F, et al. An atypical ultrastructural pattern in Fabry's disease: a study on its nature and incidence in 7 cases. Ultrastruct Pathol 1990; 14:467-474.

3. Bird TD, Lagunoff D. Neurological manifestations of Fabry disease in female carriers. Ann Neurol 1978; 4: 537-540.

4. Hozumi I, Nishizawa M, Ariga $T$, et al. Accumulation of glycosphingolipids in spinal and sympathetic ganglia of a symptomatic heterozygote of Fabry disease. J Neurol Sci 1989; 90: 273-280.

5. Ropers HH, Wienker TF, Grimm T, Schroetter K, Bender K. Evidence for preferential X-chromosome inactivation in a family with Fabry disease. Am J Hum Genet 1977; 29: 361-370.

6. Bradley J, Boden-Abala B, Lin I-F, Sacco R. Stroke in the young in the Northern Manhattan Stroke Study. Stroke 2002; 2789-2793.

7. Adams HP Jr, Kappelle LJ, Biller J, et al. Ischemic stroke in young adults. Experience in 329 patients enrolled in the Iowa registry of stroke in young adults. Arch Neurol 1995; 52: 491-495.

8. Bogousslavsky J, Regli F. Ischemic stroke in adults younger than 30 years of age. Arch Neurol 1987; 44: 479-482.

9. Kittner SJ, Stern BJ, Wozniak M, et al. Cerebral infarction in young adults: the Baltimore-Washington Cooperative Young Stroke Study. Neurology 1998; 50: 890-894.

10. Mitsias P, Levine S. Cerebrovascular complications of Fabry's disease. Ann Neurol 1996; 40: 8-17. 